\title{
Low pressure support changes the rapid shallow breathing index (RSBI) in critically ill patients on mechanical ventilation
}

\author{
Baixos níveis de pressão de suporte alteram o índice de respiração rápida \\ e superficial (IRRS) em pacientes graves sob ventilação mecânica
}

Elaine C. Gonçalves', Elaine C. Silva², Anibal Basile Filho³, Maria Auxiliadora-Martins³ , Edson A. Nicolini², Ada C. Gastaldi'

\begin{abstract}
Background: The rapid shallow breathing index (RSBI) is the most widely used index within intensive care units as a predictor of the outcome of weaning, but differences in measurement techniques have generated doubts about its predictive value. Objective: To investigate the influence of low levels of pressure support (PS) on the RSBI value of ill patients. Method: Prospective study including 30 patients on mechanical ventilation (MV) for 72 hours or more, ready for extubation. Prior to extubation, the RSBI was measured with the patient connected to the ventilator (Drager ${ }^{\mathrm{TM}}$ Evita $\mathrm{XL}$ ) and receiving pressure support ventilation (PSV) and $5 \mathrm{cmH}_{2} \mathrm{O}$ of positive end expiratory pressure or PEEP (RSBI_MIN) and then disconnected from the VM and connected to a Wright spirometer in which respiratory rate and exhaled tidal volume were recorded for $1 \mathrm{~min}$ (RSBI_ESP). Patients were divided into groups according to the outcome: successful extubation group (SG) and failed extubation group (FG). Results: Of the 30 patients, 11 (37\%) failed the extubation process. In the within-group comparison (RSBI_MIN versus RSBI_ESP), the values for RSBI_MIN were lower in both groups: SG (34.79 \pm 4.67 and $60.95 \pm 24.64)$ and $F G(38.64 \pm 12.31$ and $80.09 \pm 20.71 ; p<0.05)$. In the between-group comparison, there was no difference in RSBI_MIN (34.79 \pm 14.67 and 38.64 \pm 12.31$)$, however RSBI_ESP was higher in patients with extubation failure: SG (60.95 \pm 24.64$)$ and FG $(80.09 \pm 20.71 ; p<0.05)$. Conclusion: In critically ill patients on MV for more than $72 h$, low levels of PS overestimate the RSBI, and the index needs to be measured with the patient breathing spontaneously without the aid of pressure support.
\end{abstract}

Keywords: ventilatory weaning; mechanical ventilation; physical therapy.

\section{Resumo}

Contextualização: O índice de respiração rápida e superficial (IRRS) tem sido o mais utilizado dentro das unidades de terapia intensiva (UTIs) como preditor do resultado do desmame, porém diferenças no método de obtenção têm gerado dúvidas quanto a seu valor preditivo. Objetivo: Verificar a influência de baixos níveis de pressão de suporte (PS) no valor do IRRS em pacientes graves. Método: Estudo prospectivo, incluindo 30 pacientes sob ventilação mecânica (VM) por 72 horas ou mais, prontos para extubação. Anteriormente à extubação, o IRRS foi obtido com o paciente conectado ao ventilador Evita-XL da DragerTM recebendo pressão de suporte ventilatório (PSV) e PEEP $=5 \mathrm{cmH}_{2} \mathrm{O}$ (IRRS_MIN) e, logo após, desconectado da VM e conectado a um ventilômetro de Wright ${ }^{\mathrm{T} M}$, onde sua frequência respiratória e o volume corrente exalado eram registrados durante 1 minuto (IRRS_ESP). Os pacientes foram divididos de acordo com o desfecho em grupo sucesso extubação (GS) e grupo insucesso extubação (Gl). Resultados: Dos 30 pacientes, 11 (37\%) falharam no processo de extubação. Na comparação intragrupos (IRRS_MIN x IRRS_ESP), os valores foram menores para o IRRS_MIN em ambos os grupos: GS $(34,79 \pm 4,67$ e 60,95 $\pm 24,64)$ e Gl $(38,64 \pm 12,31$ e 80,09 $\pm 20,71)(p<0,05)$. Na comparação intergrupos não houve diferença entre IRRS_MIN $(34,79 \pm 14,67$ e 38,64 $\pm 12,31)$, por outro lado, IRRS_ESP foi maior nos pacientes com falha na extubação: GS $(60,95 \pm 24,64)$ e GI $(80,09 \pm 20,71)(p<0,05)$. Conclusão: Em pacientes graves e sob VM acima de 72 horas, níveis mínimos de PS superestimam o IRRS, sendo necessária sua obtenção com o paciente respirando de forma espontânea sem o auxílio de PS.

Palavras-chave: desmame ventilatório; ventilação mecânica; fisioterapia.

Received: 10/18/2011 - Revised: 02/08/2012 - Accepted: 04/03/2012

'Department of Orthopaedics, Traumatology and Rehabilitation of the Locomotor System, Faculdade de Medicina de Ribeirão Preto (FMRP), Universidade de São Paulo (USP), Ribeirão Preto, SP, Brazil

${ }^{2}$ Hospital das Clinicas, FMRP, USP, Ribeirão Preto, São Paulo, Brazil

${ }^{3}$ Department of Surgery, FMRP, USP, Ribeirão Preto, SP, Brazil

Correspondence to: Ada Clarice Gastaldi, Departamento de Ortopedia, Traumatologia e Reabilitação; Universidade de São Paulo (USP), Avenida Bandeirantes, 3900, CEP 14049-900,

Ribeirão Preto, SP, Brazil, e-mail: ada@fmrp.usp.br 


\section{Introduction $\because \therefore$.}

The process of discontinuing mechanical ventilatory support consists of two steps: weaning from mechanical ventilation (WMV) and extubation. WMV goes through different stages, starting with the resolution of the acute respiratory failure (ARF) followed by daily testing of physiological and clinical measures to determine the appropriate time for removal of mechanical ventilation (MV) ${ }^{1}$.

Studies have shown that approximately $75 \%$ of patients submitted to MV are weaned abruptly, while the $25 \%$ require gradual weaning and are more susceptible to complications $^{2,3}$. In these patients, MV removal becomes a challenge, and it is often difficult to predict the outcome of extubation.

Some strategies are commonly used in order to guide the decision of removing mechanical ventilation, including indexes predictive of weaning and the spontaneous breathing trial (SBT) 4,6 . Among the predictors of weaning, the rapid shallow breathing index (RSBI) has been the most used ${ }^{6}$. It was first proposed by Yang and Tobin ${ }^{7}$, and it is expressed by the relationship between respiratory rate and tidal volume (Vt) measured by a spirometer with the patient breathing spontaneously for 1 minute. Values greater than 105 cycles/ $\mathrm{min} / \mathrm{L}$ were considered predictive of unsuccessful weaning and extubation ${ }^{7}$.

In this study ${ }^{7}$, several predictive indexes were evaluated, and the RSBI showed greater sensitivity and specificity in identifying the patients who progressed toward successful extubation. Later studies conducted to evaluate the predictive power of the RSBI to identify the outcome of weaning and extubation found differences that were primarily related to the population studied and the technique used for measurement ${ }^{8-10}$.

Currently, in some institutions, the decision to submit the patient to an SBT or extubation is often influenced by or based solely on the value of RSBI, which is usually measured once a day ${ }^{11}$. In the study by Yang and Tobin ${ }^{7}$, the RSBI was measured with the patient disconnected from the ventilator and using a spirometer. However, in clinical practice, the convenience of obtaining the RSBI from the ventilator, which facilitates the daily assessment and the process of weaning, has led authors to compare the RSBI obtained from measurements performed with the patient on ventilatory support to the one recommended by the original study by Yang and Tobin, with different results ${ }^{12-15}$.

According to Soo Hoo and Park ${ }^{16}$, only $25 \%$ of respiratory therapists from nine hospitals in Los Angeles perform weaning parameter measurements with the patient breathing spontaneously through the T-tube. In Brazil, three studies that evaluated methods of obtaining weaning parameters in different capitals (Fortaleza, Distrito Federal, and São Paulo) found differences. In Fortaleza, the RSBI measurements are performed with the patient breathing spontaneously through the T-tube ${ }^{17}$. In Distrito Federal, 95\% of hospitals obtain the parameters from the display of the ventilators, and only $5 \%$ through a spirometer ${ }^{18}$. Finally, in São Paulo, 91\% of physical therapists use the pressure support ventilation (PSV) mode between 6 and $12 \mathrm{cmH}_{2} \mathrm{O}$ to perform the measurement of RSBI during the evaluation for MV removal ${ }^{19}$.

A study performed with post-cardiac surgery patients, with MV time less than 12 hours, found no differences when comparing the two methods ${ }^{12}$. Moreover, some studies in patients who required MV for more than 72 hours ${ }^{13,14}$ demonstrated that RSBI obtained with the use of pressure support (PS) was lower when compared to the traditional method described by Yang and Tobin ${ }^{7}$.

Most of these studies evaluated patients whose score on the Acute Physiology and Chronic Health Evaluation (APACHE) II ranged from 14 to $189^{20-23}$. However, we found no studies that evaluated patients with high APACHE II indexes on admission to the intensive care unit (ICU), leaving it unclear whether these results can be extrapolated to this patient population. According to Knaus et al. ${ }^{24}$, the risk of inhospital death increases exponentially with high APACHE II values, demonstrating that these patients require longer periods of ICU and MV to reach clinical stability.

In the present study, we hypothesized that minimum levels of ventilatory support can influence the RSBI value in a population of critically ill patients, who had high values of APACHE II and required MV for more than 72 hours. Therefore, the objective of this study was to verify the influence of low levels of PS on the estimation of RSBI in critically ill patients requiring MV for more than 72 hours.

\section{Method $: \therefore$.}

The research consisted of an observational non-interventional study conducted in the general adult ICU of Hospital das Clínicas (HC), Faculty of Medicine of Ribeirão Preto (FMRP), Universidade de São Paulo (USP), Ribeirão Preto, SP, Brazil, between from 03/01/2008 to 12/31/2010. This study was approved by the Ethics Committee of $\mathrm{HC} /$ FMRP-USP under the protocol number 12741/2008. The patient's family was informed about the study and allowed their participation by signing an informed consent form. 
For inclusion, we evaluated all patients admitted to the ICU during the period of the study who were over the age of 18 , received endotracheal-tube ventilatory support (Drager ${ }^{\mathrm{TM}}$ Evita-XL) for more than 72 hours, successfully underwent the process of WMV according to the criteria followed by this institution, and were ready for extubation. Patients with a history of tracheal or laryngotracheal disease and patients with tracheostomy, accidental extubation or chronic obstructive pulmonary disease (COPD) were excluded.

\section{Study design}

For patients included in the study, we recorded personal data and data from admission lab results, MV, use of sedatives and analgesics, weaning, pre- and post-extubation hemodynamic and ventilatory parameters, and post-extubation progress. To stratify the severity of the patients by risk range and compare the number of deaths observed and expected, we used the APACHE II index, which was calculated 24 hours after admission to the ICU. All decisions about when to start weaning and extubation were made by the ICU staff of HC-FMRP.

\section{Protocol}

Extubation was performed when the WMV process was completed and the patient showed the following clinical conditions: (1) resolution of the cause of respiratory failure; (2) hemodynamic stability without vasoactive drugs; (3) state of alertness, cooperation, and response to commands; and (4) minimal levels of ventilatory support (PS $5 \mathrm{cmH}_{2} \mathrm{O}$; positive end expiratory pressure [PEEP] $5 \mathrm{cmH}_{2} \mathrm{O}$ ). The RSBI measurements were performed in two different ways: with the help of PS (PS $5 \mathrm{cmH}_{2} \mathrm{O}$; PEEP $5 \mathrm{cmH}_{2} \mathrm{O}$ ), called RSBI_ MIN, and using the method described by Yang and Tobin ${ }^{7}$, called RSBI_ESP.

Before the measurements were taken, the patient was placed in the supine position with the trunk flexed at 45 degrees. We decided to calculate the RSBI first in PS (RSBI_ MIN) by noting the respiratory rate (RR), exhaled tidal volume (EVt), and minute volume (VE) obtained from the ventilator's display as the patient was already connected to the MV. In this method, the tube's automatic compensation mode was turned off. After obtaining the RSBI_MIN, the patient was disconnected from the MV, and a spirometer was connected to the endotracheal tube to measure the RSBI_ESP.
After that, the patient was connected with a T-tube to an oxygen-enriched source for 30 minutes. If, prior to that time, the patient showed signs of intolerance to disconnection from MV, ventilatory support was resumed and extubation was postponed. Patients who passed the T-tube test successfully were subsequently extubated.

\section{Statistical analysis}

The results are expressed as mean and standard deviation. To compare the mean between the different methods, the Wilcoxon test was applied. The significance level was set at 0.05 or $5 \%$.

\section{Results $: \because$.}

During the study period, 30 patients met the inclusion criteria. Of these, 11 (37\%) failed the process of extubation and were reintubated. Patients were divided into groups according to the outcome: successful extubation group (SG) and failed extubation group (FG). The reasons that led to the need for MV as well as the demographic and clinical characteristics are listed in Tables 1 and 2, respectively. In the comparison of the demographic data, there was no significant difference between groups.

The results from the RSBI evaluation under different conditions are shown in Figure 1. In the within-group comparison between the two measurement methods (RSBI_MIN versus RSBI_ESP), the RSBI_MIN values were much lower, and this result was observed in both groups: SG (34.78 \pm 14.65 and $60.94 \pm 24.64)$ and FG $(38.63 \pm 12.31$ and $80.09 \pm 20.71 ; \mathrm{p}<0.05)$, as shown in Table 3 .

In the between-group comparison, there was no significant difference between the values for RSBI_MIN

Table 1. Reasons for need of mechanical ventilation.

\begin{tabular}{lcc}
\hline Reasons for mechanical ventilation & Total & $\%$ \\
\hline Septic shock & 15 & 50 \\
\hline Postoperative state & 4 & 13.33 \\
\hline Neurological disease & 3 & 10 \\
\hline Infection & 2 & 6.66 \\
\hline Neoplasia & 3 & 10 \\
\hline Heart failure & 2 & 6.66 \\
\hline Others & 1 & 3.33 \\
\hline
\end{tabular}


(34.78 \pm 14.65 and $38.63 \pm 12.31)$. In contrast, the RSBI_ESP was higher in the FG compared to the SG $(80.09 \pm 20.71$ and 60.94 $\pm 24.64 ; \mathrm{p}<0.05)$. In the $F G$, only one patient showed RSBI>105 cycles/min/L at the time of extubation.

\section{Discussion $\because \therefore$.}

This study compared RSBI measurements obtained with the aid of PSV to measurements obtained in accordance with criteria established by Yang and Tobin ${ }^{7}$, demonstrating that the use of ventilatory support can change the RSBI value in a population of critically ill patients who required MV for more than 72 hours. In an ICU, it is routine to perform clinical evaluations and daily evaluations of weaning parameters in an attempt to identify patients who are able to conduct an SBT and, thus, be extubated as early as possible to avoid complications associated with the long-term use of MV. Therefore, weaning parameters are used as tools to guide the decision to extubate these patients and must not be difficult to reproduce or require major technological devices that could hinder its daily performance. One of the reasons the RSBI is used so often in the ICU is precisely the fact that it fulfills these requirements: it is simple to obtain and it does not require invasive methods or the patient's cooperation.

Despite the ease of reproduction of the RSBI, the technological evolution of mechanical ventilators has already made the RSBI calculation available on the display of some MV models in order to provide more security and benefits to critically ill patients ${ }^{25}$. This convenience, combined with the absence of potential respiratory distress to the patient when disconnected from MV, justifies investigations aimed at comparing the effect of PS on the calculation of the RSBI as well as its predictive value $\mathrm{e}^{10,12,14}$.

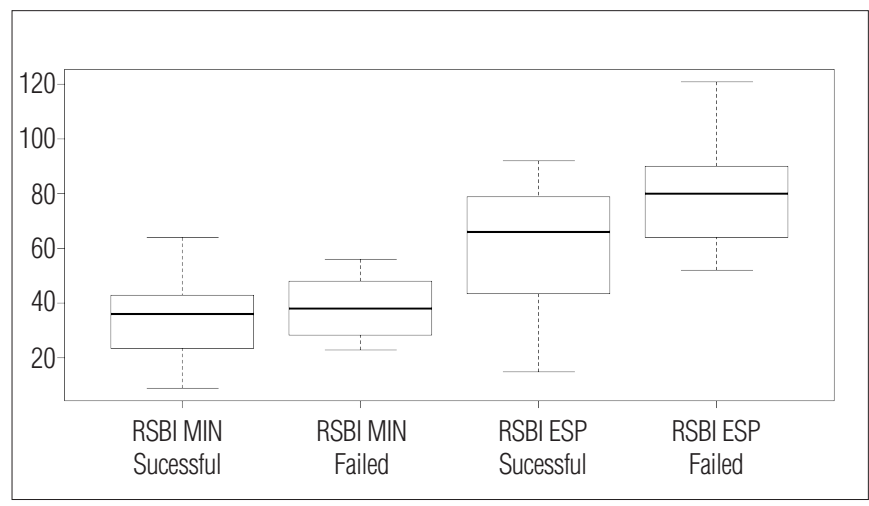

Figure 1. Graphic representation of the median, lower and upper quartiles, and interquartile range of the RSBI_MIN and RSBI_ESP values, respectively, separated by group.

Table 2. Mean values and standard deviations of demographic and clinical data by group.

\begin{tabular}{lcccc}
\hline Variable & Total & Successful & Failed & value \\
\hline Sample & 30 & 19 & 11 & NS \\
\hline APACHE II & $23.97 \pm 6.69$ & $23.89 \pm 7.17$ & $24.09 \pm 6.09$ & NS \\
\hline Death risk & $48.27 \pm 22.06$ & $46.32 \pm 23.34$ & $51.64 \pm 20.28$ & NS \\
\hline Age & $61.47 \pm 14.54$ & $61.84 \pm 14.30$ & $60.82 \pm 15.63$ & NS \\
\hline Sedation days & $2.63 \pm 2.31$ & $2.47 \pm 1.47$ & $2.91 \pm 3.39$ & NS \\
\hline Intubation days & $6.20 \pm 3.17$ & $5.32 \pm 2.50$ & $7.73 \pm 3.72$ & NS \\
\hline Days start weaning & $4.17 \pm 3.02$ & $3.53 \pm 1.98$ & $5.27 \pm 4.15$ & NS \\
\hline Weaning days & $2.07 \pm 1.48$ & $1.89 \pm 1.33$ & $2.36 \pm 1.75$ & NS \\
\hline
\end{tabular}

Total: All patients; Successful: successful extubation; Failed: unsuccessful extubation; APACHE II: Acute Physiology and Chronic Health Evaluation; NS: no statistical significance. Values are the means \pm SD.

Table 3. Mean values, standard deviation, minimum, median, and maximum values of RSBI for the different measurement methods separated by groups.

\begin{tabular}{|c|c|c|c|c|c|c|c|}
\hline Group & Sample & Variable & Mean & SD & Minimum & Median & Maximum \\
\hline \multirow{2}{*}{ Successful } & \multirow{2}{*}{19} & RSBI_ESP & 60.95 & 24.64 & 15.00 & 66.00 & 92.00 \\
\hline & & RSBI_MIN & 34.79 & 14.67 & 9.00 & 36.00 & 64.00 \\
\hline \multirow{2}{*}{ Failed } & \multirow{2}{*}{11} & RSBI_ESP & 80.09 & 20.71 & 52.00 & 80.00 & 121.00 \\
\hline & & RSBI_MIN & 38.64 & 12.31 & 23.00 & 38.00 & 56.00 \\
\hline
\end{tabular}

RSBI_MIN: Rapid shallow breathing index obtained with ventilatory support $\left(\mathrm{PS}=5 \mathrm{cmH}_{2} \mathrm{O}\right.$ and $\left.\mathrm{PEEP}=5 \mathrm{cmH}, 0\right)$; RSBI_ESP: Rapid shallow breathing index obtained with patient breathing room air; SD: Standard Deviation. 
In Brazil, some studies that evaluated the methods of measurement of weaning parameters demonstrated great variability among methods and criteria. To calculate the RSBI, the method with the patient breathing without the aid of ventilatory support was the most common in Fortaleza ${ }^{17}$. Moreover, the use of the ventilatory support to obtain RSBI was common in hospitals in Distrito Federal ${ }^{18}$ and São Paulo $^{19}$. Even in the nation's capital district, Distrito Federal, only five ICUs had a spirometer.

Brochard et al. ${ }^{3}$ suggest that a PS of $7-8 \mathrm{cmH}_{2} \mathrm{O}$ is sufficient to compensate for the resistance imposed by the endotracheal tube. However, according to Stroetz and Hubmayr $^{26}$, the higher the level of PS supplied, the lower the RR and the higher the Vt of the patient, and the smaller the RSBI value will be.

Previous studies have already demonstrated that specific populations may benefit from PSV during the weaning process, including patients with COPD. In this context, the use of positive pressure in the SBT facilitates the elimination of carbon dioxide due to a decrease in RR and an increase in Vt and inspiratory effort as a result of the reduction in intrinsic PEEP ${ }^{27,28}$. Another group that may benefit from the use of PS during the evaluation of weaning is patients with heart disease. The use of positive pressure in these patients improves cardiac function due to an increase in intrathoracic pressure, which reduces the pre- and post-load, improving the ejection fraction of the left ventricle, and thus reducing respiratory work and effort ${ }^{29}$.

In the present study, a small minority of the population had heart disease, and patients with COPD were excluded due to previous changes in pulmonary mechanics in these patients. Minimum values of PS $\left(5 \mathrm{cmH}_{2} \mathrm{O}\right.$ and $5 \mathrm{cmH}_{2} \mathrm{O}$ PEEP) were used so that only the resistance of the tube was compensated and the influence of PS was minimal or nonexistent. The results showed that ventilatory support, even at low levels, can influence the value of RSBI in another group of patients, consisting of those with high APACHE II values. When the RSBI was measured with PSV, there was a decrease in its value, which was common to the SG and FG. In both groups, the difference between the two methods is significant with lower values for the method with the use of PS.

Similar results can be observed in the study by Santos et al. ${ }^{14}$ who investigated the RSBI value obtained in modalities PSV (10 $\mathrm{cmH}_{2} \mathrm{O}$ and $5 \mathrm{cmH}_{2} \mathrm{O}$ PEEP), continuous positive airway pressure (CPAP) $\left(5 \mathrm{cmH}_{2} \mathrm{O}\right)$, and spontaneous ventilation in 54 patients in a general ICU and coronary care unit, showing that the RSBI value obtained in the PSV mode was significantly lower than that obtained in the CPAP and spontaneous breathing modes. Fiore Júnior et al. ${ }^{30}$ also evaluated the effects of PS on the measurement of RR, Vt, MM, and RSBI in 26 patients who underwent coronary artery bypass grafting and compared them to values obtained with the patient breathing spontaneously prior to extubation, showing lower values when obtained with PSV.

The same reduction in RSBI values was observed in studies that used CPAP. Patel et al. ${ }^{13}$ evaluated the RSBI in 60 patients on MV using two different methods (CPAP of 5 $\mathrm{cmH}_{2} \mathrm{O}$ and T-tube) and found lower values for the measurements with ventilatory support, concluding that it can have a significant effect on the RSBI. In the study by Desai, Myers, and Simeone ${ }^{31}$, there was a decrease of $19.1 \%$ in the RSBI value obtained in the CPAP of $5 \mathrm{cmH}_{2} \mathrm{O}$ compared to that obtained with the patient disconnected from the MV.

One explanation for these results to be repeated in this study population may be related to the fact that patients with high APACHE II values have a worse clinical condition, with multiple organ dysfunction, thereby increasing the risk of hospital death ${ }^{24}$ and contributing to longer periods of MV and intensive care. The increased length of ICU stay and the immobility subsequently lead to impairment of the musculoskeletal, gastrointestinal, urinary, cardiovascular, respiratory, and cutaneous systems ${ }^{32}$.

In this context, the PS may have benefited lung mechanics by reducing the respiratory work imposed by the endotracheal tube in patients with lower respiratory reserve, worse clinical condition, and poor cardiovascular and musculoskeletal conditioning. Moreover, when placed in spontaneous breathing, they experienced a greater resistance owing to the presence of the endotracheal tube, which requires more respiratory work and causes increased RR and decreased Vt, both parameters needed for calculating the RSBI.

In the analysis of the RSBI value obtained in PS, there was no significant difference between the SG and the FG. In contrast, the RSBI value obtained with the patient disconnected from the ventilator was higher in the FG than in the SG, showing the superior predictive ability of this method.

There are already studies that demonstrate significantly lower values of RSBI in populations who progressed toward successful extubation. In the study by Capdevila et al. ${ }^{33}$, the group that progressed toward successful extubation showed lower RSBI values $(50 \pm 23)$ compared to the failure group (69 \pm 25$)$.

Recently, a cutoff of RSBI $\leq 57$ cycles/min/L was suggested for patients with $M V>48$ hours who successfully passed the SBT as a predictor of successful extubation in medical ICU patients from eight countries. The same group 
of authors subsequently evaluated extubation failure in 1152 patients with scheduled extubation and found mean RSBI values of 48 in the patients who developed successful extubation $^{34,35}$. In our study, the mean value for RSBI in patients who progressed toward extubation was 61 in spontaneously breathing, compared to 35 in PS.

It must be highlighted that the absence of randomization to establish the order of RSBI measurement can be considered a methodological limitation of the study. However, this is the model used by other authors in the literature ${ }^{10,12,14,33}$, which provides some reason for the non-random procedure. The method reproduces clinical routine, in which measurements are taken with the patient disconnected from the ventilator after ventilatory support. Additionally, the measurements without ventilatory support last only one minute and, regardless of the order of the steps, this timeframe would not be sufficient to promote stabilization of RR and Vt in this method, unlike the measurement with ventilatory support that requires waiting for stabilization before each measurement.

\section{Conclusion $\because:$.}

Our study showed that, in patients with high APACHE II values, minimal PS values can affect the RSBI value and that the best method of evaluating the ventilatory condition of a patient is the RSBI obtained in spontaneous breathing without the aid of PS.

\section{References $: \because$.}

1. Boles JM, Bion J, Connors A, Herridge M, Marsh B, Melot C, et al. Weaning from mechanical ventilation. Eur Respir J. 2007;29(5):1033-56.

2. Esteban A, Frutos F, Tobin MJ, Alía I, Solsona JF, Valverdú I, et al. A comparison of four methods of weaning patients from mechanical ventilation. Spanish Lung Failure Collaborative Group. N Engl J Med. 1995;332(6):345-50

3. Brochard L, Rauss A, Benito S, Conti G, Mancebo J, Rekik N, et al. Comparison of three methods of gradual withdrawal from ventilatory support during weaning from mechanical ventilation. Am J Respir Crit Care Med. 1994;150(4):896-903

4. Esteban A, Alía I, Tobin MJ, Gil A, Gordo F, Vallverdú I, et al. Effect of spontaneous breathing trial duration on outcome of attempts to discontinue mechanical ventilation. Spanish Lung Failure Collaborative Group. Am J Respir Crit Care Med. 1999;159(2):512-8.

5. Cohen JD, Shapiro M, Grozovski E, Singer P. Automatic tube compensation-assisted respiratory rate to tidal volume ratio improves the prediction of weaning outcome. Chest. 2002;122(3):980-4.

6. Meade M, Guyatt G, Cook D, Griffith L, Sinuff T, Kergl C, et al. Predicting success in weaning from mechanical ventilation. Chest. 2001;120(Suppl 6):401-23.

7. Yang KL, Tobin MJ. A prospective study of indexes predicting the outcome of trials of weaning from mechanical ventilation. N Engl J Med. 1991;324(21):1445-50.

8. Vidotto MC, Sogame LC, Calciolari CC, Nascimento OA, Jardim JR. The prediction of extubation success of postoperative neurosurgical patients using frequency-tidal volume ratios. Neurocrit Care. 2008;9(1):83-9.

9. Teixeira C, Zimermann Teixeira PJ, Hohër JA, De Leon PP, Brodt SF, Moreira JS. Serial measurements of $f / V T$ can predict extubation failure in patients with $f / N T \leq 105$ ? J Crit Care. 2008;23(4):572-6.

10. EL-Khatib MF, Zeineldine SM, Jamaleddine GW. Effect of pressure support ventilation and positive end expiratory pressure on the rapid shallow breathing index in intensive care unit patients. Intensive Care Med. 2008;34(3):505-10.

11. Ely EW, Baker AM, Dunagan DP, Burke HL, Smith AC, Kelly PT, et al. Effect on the duration of mechanical ventilation of identifying patients capable of breathing spontaneously. N Engl J Med. 1996;335(25):1864-9

12. Lessa FAM, Paes CD, Tonella RM, Araújo S. Comparison of the rapid shallow breathing index (RSBI) calculated under direct and indirect form on the postoperative period of cardiac surgery. Rev Bras Fisioter. 2010;14(6):503-9.
13. Patel KN, Ganatra KD, Bates JHT, Young MP. Variation in the rapid shallow breathing index associated with common measurement techniques and conditions. Respir Care. 2009;54(11):1462-6.

14. Santos LO, Borges MR, Figueiredo LC, Guedes CAV, Vian BS, Kappaz K, et al Comparação entre três métodos de obtenção do índice de respiração rápida e superficial em pacientes submetidos ao desmame da ventilação mecânica. Rev Bras Ter Intensiva. 2007;19(3):331-6.

15. Lee KH, Hui KP, Chan TB, Tan WC, Lim TK. Rapid shallow breathing (frequency-tidal volume ratio) did not predict extubation outcome. Chest. 1994;105(2):540-3.

16. Soo Hoo GW, Park L. Variations in the measurement of weaning parameters: A survey of respiratory therapists. Chest. 2002;121(6):1947-55.

17. Mont'Alverne DGB, Lino JA, Bizerril DO. Variações nas mensuração dos parâmetros de desmame da ventilação mecânica em hospitais da cidade de Fortaleza. Rev Bras Ter Intensiva. 2008;20(2):149-53.

18. Gonçalves JQ, Martins RC, Andrade APA, Cardoso FPF, Melo MHO. Características do processo de desmame da ventilação mecânica em hospitais do Distrito Federal. Rev Bras Ter Intensiva. 2007;19(1):38-43.

19. Rodrigues MM, Fiore JFJ, Benassule E, Chiavegato LD, Cavalheiro LV, Beppu OS. Variação na mensuração dos parâmetros da ventilação mecânica em hospitais da cidade de São Paulo. Rev Bras Fisioter. 2004;(Suppl):177.

20. Epstein SK. Etiology of extubation failure and the predictive value of the rapid shallow breathing index. Am J Respir Crit Care Med. 1995;152(2):545-9.

21. Chatila W, Jacob B, Guaglionone D, Manthous CA. The unassisted respiratory rate-tidal volume ratio accurately predicts weaning outcome. Am J Med. 1996;101(1):61-7.

22. Kuo PH, Wu HD, Lu BY, Chen MT, Kuo SH, Yang PC. Predictive value of rapid shallow breathing index measured at initiation and termination of a 2-hour spontaneous breathing trial for weaning outcome in ICU patients. J Formos Med Assoc. 2006;105(5):390-8.

23. Danaga AR, Gut AL, Antunes LCO, Ferreira ALA, Yamaguti FA, Christovan JC, et al. Avaliação do desempenho diagnostico e do valor de corte para o índice de respiração rápida e superficial na predição do insucesso da extubação. J Bras Pneumol. 2009;35(6):541-7.

24. Knaus WA, Wagner DP, Draper EA, Zimmerman JE, Bergner M, Bastos PG, et al. The APACHE III prognostic system. Risk prediction of hospital mortality for critically ill hospitalized adults. Chest. 1991;100(6):1619-36 
25. Toufen Júnior C, Carvalho CRR. III Consenso brasileiro de ventilação mecânica - ventiladores mecânicos. J Bras Pneumol. 2007;33(Supl 2):S71-91.

26. Stroetz RW, Hubmayr RD. Tidal volume maintenance during weaning with pressure support. Am J Respir Crit Care Med. 1995;152(3):1034-40.

27. Reissmann HK, Ranieri VM, Goldberg P, Gottfried SB. Continuous positive airway pressure facilitates spontaneous breathing in weaning chronic obstructive pulmonary disease patients by improving breathing pattern and gas exchange. Intensive Care Med. 2000;26(12):1764-72.

28. Sydow M, Golisch W, Buscher H, Zinserling J, Crozier TA, Burchardi H. Effect of low-level PEEP on inspiratory work of breathing in intubated patients, both with healthy lungs and with COPD. Intensive Care Med. 1995;21(11):887-95.

29. Naughton MT, Rahman M, Hara K, Flora JS, Bradley D. Effect of continuous positive airway pressure on intrathoracic and left ventricular transmural pressures in patients with congestive heart failure. Circulation. 1995;91(6):725-31.
30. Fiore Júnior JF, Oliveira ACS, Pinho E, Benassule E, Francischini J, Chiavagato LD, et al. 0 uso de baixos níveis de pressão suporte influencia a avaliação de parâmetros de desmame? Rev Bras Ter Intensiva. 2004;16(3):146-9.

31. Desai NR, Myers L, Simeone F. Comparison of 3 different methods used to measure the rapid shallow breathing index. J Crit Care. 2011 [Epub ahead of print].

32. Fredericks CM. Adverse effects of immobilization on the musculoskeletal system. In: Fredericks CM, Saladim LK, editors. Pathophysiology of the motor systems: principles and clinical presentations. Philadelphia: F.A. Davis Company; 1996. p. 537-51.

33. Capdevila XJ, Perrigault PF, Perey PJ, Roustan JP, d'Athis F. Occlusion pressure its ratio to maximum inspiratory pressure are useful predictors for successful extubation following T-piece weaning trial. Chest. 1995;108(2):482-9.

34. Frutos-Vivar F, Esteban A, Apezteguia C, González M, Arabi Y, Restrepo MI, et al. Outcome of reintubated patients after scheduled extubation. J Crit Care. 2011;26(5):502-9.

35. Frutos-Vivar F, Ferguson ND, Esteban A, Epstein SK, Arabi Y, Apezteguía C, et al. Risk factors for extubation failure in patients following a successful spontaneous breathing trial. Chest. 2006;130(6):1664-71. 